\title{
Diamond growth in premixed propylene-oxygen flames
}

\author{
Ho Seon Shin and David G. Goodwin \\ Division of Engineering and Applied Science, California Institute of Technology, \\ Pasadena, California 91125
}

(Received 21 December 1994; accepted for publication 24 March 1995)

\begin{abstract}
Diamond film growth in low-pressure premixed propylene/oxygen flames is demonstrated. Well-faceted films are grown at a pressure of 180 Torr and a fuel/oxygen ratio of 0.47 . Using propylene as the fuel may greatly improve the economics of flame synthesis of diamond, since propylene is an order of magnitude cheaper than acetylene. (C) 1995 American Institute of Physics.
\end{abstract}

The combustion method is a promising technique for diamond synthesis. High-quality, transparent wafers have been grown at atmospheric pressure. ${ }^{1-3}$ In addition, by working at low pressure, it is possible to deposit uniform films over large areas with modest substrate cooling requirements. 4,5

Since the original demonstration by Hirose and Mitsuizumi ${ }^{6}$ using an oxyacetylene welding torch, most studies of combustion synthesis of diamond have used acetylene/ oxygen flames. An energetic fuel such as acetylene is required, since atomic hydrogen plays a crucial role in diamond growth chemistry. ${ }^{7,8}$ Consequently, the flame must be able to produce and deliver to the substrate a large flux of atomic hydrogen. This requires a hot, fast flame.

Unfortunately, acetylene is expensive and difficult to handle, since it may detonate even in the absence of oxygen, and is highly flammable in air. The cost of acetylene has been identified as the dominant cost of diamond produced by the combustion method, ${ }^{1}$ and this cost currently keeps the combustion method from being competitive with plasma methods, despite its potential advantages for large area deposition. Clearly, if other, less expensive fuels could replace acetylene, the cost of diamond produced by combustion synthesis would be greatly reduced.

Several possible alternative fuels are compared to acetylene in Table I. At atmospheric pressure, it is reasonable to assume that the combustion products are close to chemical equilibrium. Consequently, useful measures of diamond growth potential are the equilibrium adiabatic flame temperature and the equilibrium atomic hydrogen mole fraction. The values listed in Table I are calculated for a 1:1 C:O ratio, since diamond deposition flames must be run close to this fuel/oxygen ratio to achieve the gas composition needed for diamond growth (a reducing flame with high $\mathrm{H}$ and moderately low residual hydrocarbon concentrations).

The results in Table I show that only a few fuels produce flames in oxygen which are hot enough to achieve greater than $1 \%$ atomic hydrogen at equilibrium at a $1: 1 \mathrm{C}: \mathrm{O}$ ratio. This suggests that only these fuels are likely candidates for diamond growth under conditions where chemical equilibrium prevails.

To date, diamond has been grown with two hydrocarbon fuels other than acetylene. Carrington et al. ${ }^{9}$ deposited isolated diamond particles using ethylene/oxygen flames at atmospheric pressure, and Kim and Cappelli ${ }^{10}$ grew continuous films with ethylene/oxygen at 50 Torr. Harris, Shin, and Goodwin $^{11}$ recently grew continuous films at $70-180$ Torr using flames burning "MAPP gas," a commercially available stabilized mixture of propadiene and methyl acetylene in LPG gas (primarily propylene). The $\mathrm{C}_{3} \mathrm{H}_{4}$ (propadiene + methyl acetylene) content of MAPP gas is $\sim 45 \%$, and the successful diamond growth with this fuel was attributed to these energetic species. There have been no reports of attempts to grow diamond in benzene/oxygen flames, although benzene should be a promising candidate.

In this letter, we report growth of diamond films in propylene/oxygen and propylene/propane/oxygen flames at low pressure. That diamond may be grown in these flames is surprising, since the heat of formation, adiabatic flame temperature, and equilibrium $\mathrm{H}$ mole fraction are all significantly less than even ethylene/oxygen. Since, as discussed below, propylene is an order of magnitude cheaper than acetylene and is much easier to handle, the ability to use propylene as the fuel may greatly improve the economics of combustion synthesis of diamond.

The experiments were carried out in the same lowpressure combustion facility we have used previously for diamond growth with acetylene/oxygen ${ }^{4}$ and MAPP/ oxygen ${ }^{11}$ flames. Premixed propylene $/ \mathrm{O}_{2}$ flames were stabilized on a water-cooled burner $(2 \mathrm{~cm}$ diam $)$ housed in a water-cooled bell jar vacuum chamber. The burner face is copper, and the fuel/oxygen mixture emerges through an array of $1 \mathrm{~mm}$ diam holes spaced $2 \mathrm{~mm}$ apart. Experiments were conducted using both silicon wafers and molybdenum disks $(5 \mathrm{~cm}$ diam, $0.6 \mathrm{~cm}$ thick) as substrates. The substrate is radiatively cooled, and typically reaches a steady-state temperature of approximately $800{ }^{\circ} \mathrm{C}$ during growth. The substrate temperature is measured with a two-color pyrometer.

TABLE I. Heat of formation, adiabatic flame temperature, and equilibrium atomic hydrogen mole fraction for selected hydrocarbon fuels. The equilibrium calculations are for a $\mathrm{C}: \mathrm{O}$ ratio of 1 and a pressure of $1 \mathrm{~atm}$.

\begin{tabular}{lrcc}
\hline \hline Fuel & $\begin{array}{c}\Delta H_{f}^{0} \\
\mathrm{~kJ} / \mathrm{mol}\end{array}$ & $\begin{array}{c}T_{\text {flame }} \\
(\mathrm{K})\end{array}$ & \multicolumn{1}{c}{$X_{H}$} \\
\hline Acetylene $\left(\mathrm{C}_{2} \mathrm{H}_{2}\right)$ & 228.0 & 3325 & 0.179 \\
1,2-propadiene $\left(\mathrm{C}_{3} \mathrm{H}_{4}\right)$ & 190.8 & 2924 & 0.073 \\
Methyl acetylene $\left(\mathrm{C}_{3} \mathrm{H}_{4}\right)$ & 186.6 & 2907 & 0.069 \\
Benzene $\left(\mathrm{C}_{6} \mathrm{H}_{6}\right)$ & 82.8 & 2614 & 0.023 \\
Ethylene $\left(\mathrm{C}_{2} \mathrm{H}_{4}\right)$ & 52.3 & 2330 & $7.9 \times 10^{-3}$ \\
Propylene $\left(\mathrm{C}_{3} \mathrm{H}_{6}\right)$ & 20.1 & 2096 & $2.1 \times 10^{-3}$ \\
Methane $\left(\mathrm{CH}_{4}\right)$ & -74.5 & 1024 & $3.6 \times 10^{-9}$ \\
Ethane $\left(\mathrm{C}_{2} \mathrm{H}_{6}\right)$ & -84.1 & 1237 & $3.0 \times 10^{-7}$ \\
Propane $\left(\mathrm{C}_{3} \mathrm{H}_{8}\right)$ & -104.6 & 1367 & $2.3 \times 10^{-6}$ \\
\hline \hline
\end{tabular}




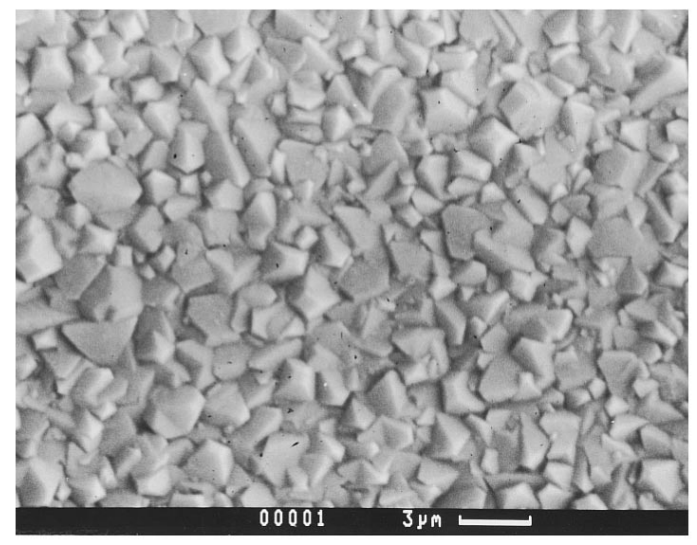

FIG. 1. A diamond film grown in a propylene/oxygen flame.

Two different sources of propylene gas were used. The first was a commercially available mixture of propylene and propane ("HPG" gas, Airco, greater than $80 \%$ propylene) and the second was $99.0 \%$ propylene (Matheson). Diamond was grown using both gases, and the conditions were very similar. The pressure used for this work was 180 Torr, which is also the pressure at which the best diamond was grown previously in MAPP/oxygen flames. ${ }^{11}$

A typical diamond film grown with HPG is shown in Fig. 1. This film was grown for $3 \mathrm{~h}$, with a total flow rate (fuel and oxygen) of 1.88 standard liters per minute (slm) per $\mathrm{cm}^{2}$ of burner area. The fuel/oxygen ratio was $0.47(\mathrm{C}: \mathrm{O}$ $=0.70)$. The substrate temperature was $800{ }^{\circ} \mathrm{C}$, and the separation between the burner and substrate was $4.25 \mathrm{~mm}$. The film thickness was $2.7 \mu \mathrm{m}$ after $3 \mathrm{~h}$, from which the diamond film growth rate was estimated to be $0.9 \mu \mathrm{m} / \mathrm{h}$. A Raman spectrum of this film is shown in Fig. 2.

As with our previous work with $\mathrm{MAPP} / \mathrm{O}_{2}$ flames, the diamond films were nonuniform, since the burner hole spacing $(2 \mathrm{~mm})$ was comparable to the burner/substrate separation $(4.25 \mathrm{~mm})$. Only a small portion of the substrate was found to contain diamond such as shown in Fig. 1. The remainder of the substrate had either no deposit or nondiamond carbon. We believe that an optimized burner design could greatly improve the film uniformity and area coverage.

The observed $\mathrm{C}: \mathrm{O}$ ratio for diamond growth (0.7) would produce an oxidizing flame at equilibrium, which would be

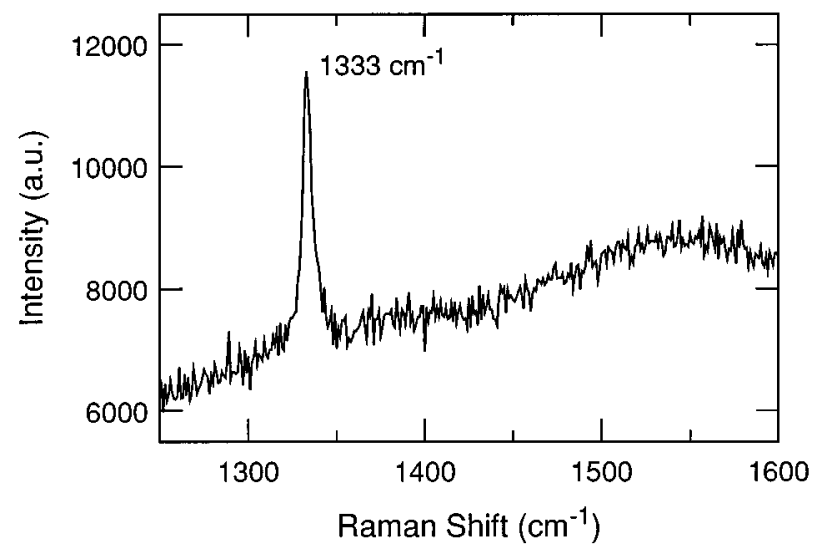

FIG. 2. Raman spectrum of the film shown in Fig. 1. unable to deposit diamond. The need for a lower $\mathrm{C}$ : O ratio than that needed at equilibrium indicates that nonequilibrium flame chemistry is important at this pressure. This is consistent with other low-pressure flame growth experiments ${ }^{4,10,12}$ and with simulation results. ${ }^{4,13,14}$ We have simulated the present flame conditions using the propylene oxidation mechanism of Dagaut, Cathonnet, and Boettner, ${ }^{15}$ and find a peak flame temperature of $2800 \mathrm{~K}$ and a peak $\mathrm{H}$ mole fraction $2.4 \times 10^{-2}$. We suggest that it is this nonequilibrium which allows fuels such as propylene to deposit diamond, even though they should be poor candidates based on the comparison in Table I. This suggests that still other fuels may be worth considering for diamond growth at low pressure.

The ability to grow diamond in propylene/oxygen flames may significantly improve the viability of the combustion synthesis method, and may finally make it competitive with plasma methods. Since propylene is produced industrially in great quantities, it is inexpensive and readily available. Propylene is safer than acetylene, ethylene, or MAPP gas. Its flammability limits in air are $2 \%-11.1 \%$, compared to $2.7 \%-36 \%$ for ethylene, and $2.5 \%-100 \%$ for acetylene. It may also be easily stored as a liquid, unlike acetylene or ethylene.

We can make a tentative economic comparison between acetylene and propylene use for diamond growth. The efficiency in converting fuel carbon atoms into diamond is given by the ratio of the diamond mass deposition rate $\left(\mathrm{g} / \mathrm{cm}^{2} / \mathrm{s}\right)$ to the carbon mass flow rate $\left(\mathrm{g} / \mathrm{cm}^{2} / \mathrm{s}\right)$. The present results with propylene yield a carbon-conversion efficiency of 5.5 $\times 10^{-6}$ at $800{ }^{\circ} \mathrm{C}$. This may be compared to the value of $7.5 \times 10^{-6}$ for acetylene for the same substrate temperature. This acetylene value comes from growth at low pressure (52 Torr) in the same facility as the present experiments, ${ }^{4}$ but typical values for atmospheric-pressure methods are very similar. The cost of propylene in large quantities is approximately $\$ 0.18 / \mathrm{lb}$, which is less than that of ethylene $(\$ 0.22-\$ 0.24 / \mathrm{lb}) .{ }^{16}$ In contrast, acetylene costs $\$ 1.45-\$ 2.00 / \mathrm{lb}$, depending on purity. Therefore, since the carbon-conversion efficiency for propylene is only slightly lower than that for acetylene, while its cost is an order of magnitude lower, switching from acetylene to propylene may be able to lower the fuel cost per unit mass of diamond by roughly a factor of seven. This may well make the combustion method competitive with arcjet, microwave, and hot filament methods for many applications.

We wish to thank Max Bachrach for performing the Raman analysis, and Adam Singer for supplying gas price information. This work is supported, in part, by grants from the National Science Foundation and the Naval Research Laboratory.

${ }^{1}$ K. V. Ravi, C. A Koch, and D. Olson, in Proceedings of the 2nd International Conference on Applied Diamond Films and Related Materials, edited by M. Yoshikawa, M. Murakawa, Y. Tzeng, and W. A. Yarbrough (MYU, Tokyo, 1993), pp. 491-496.

${ }^{2}$ M. Murayama and K. Uchida, Combustion and Flame 91, 239 (1992).

${ }^{3}$ K. F. McCarty, E. Meeks, R. J. Kee, and A. E. Lutz, Appl. Phys. Lett. 63, 1498 (1993)

${ }^{4}$ N. G. Glumac and D. G. Goodwin, Mater. Lett. 18, 119 (1993).

${ }^{5}$ H. S. Shin, N. G. Glumac, and D. G. Goodwin, in Proceedings of the 4th 
International Conference on New Diamond Science and Technology, edited by S. Saito, N. Fujimori, O. Fukunaga, M. Kamo, K. Kobashi, and M. Yoshikawa (MYU, Tokyo, 1994), pp. 27-30.

${ }^{6}$ Y. Hirose and M. Mitsuizumi, New Diamond 4, 34 (1988).

${ }^{7}$ J. C. Angus, Y. Wang, and M. Sunkara, Annu. Rev. Mater. Sci. 21, 221 (1991).

${ }^{8}$ J. E. Butler and R. L. Woodin, Trans. R. Soc. London 342, 209 (1993).

${ }^{9}$ W. A. Carrington, L. M. Hansseon, K. A. Snail, D. B. Oakes, and J. E. Butler, Metall. Trans. A 20A, 1282 (1989).

${ }^{10}$ J. S. Kim and M. A. Capelli, Appl. Phys. Lett. 65, 2786 (1994).
${ }^{11}$ S. J. Harris, H. S. Shin, and D. G. Goodwin, Appl. Phys. Lett. 66, 891 (1995).

${ }^{12}$ J. A. Cooper, Jr. and W. A. Yarbrough, SPIE Proc. 1325, 41 (1990).

${ }^{13}$ E. Meeks, R. J. Kee, D. S. Dandy, and M. E. Coltrin, Combustion and Flame 92, 144 (1993).

${ }^{14}$ J. S. Kim and M. A. Capelli, J. Appl. Phys. 72, 5461 (1992).

${ }^{15}$ P. Dagaut, M. Cathonnet, and J. C. Boettner, Comb. Sci. Technol. 83, 167 (1992).

${ }^{16}$ D. Smock, Plastics World 52, 67 (1994). 